\title{
Nosocomiicoccus ampullae gen. nov., sp. nov., isolated from the surface of bottles of saline solution used in wound cleansing
}

\author{
Marta Alves, ${ }^{1}$ Célia Nogueira, ${ }^{1}$ Augusto de Magalhães-Sant'Ana, ${ }^{1}$ \\ Ana Paula Chung, ${ }^{2}$ Paula V. Morais ${ }^{2,3}$ and Milton S. da Costa ${ }^{3}$ \\ ${ }^{1}$ Institute of Microbiology, Faculty of Medicine, University of Coimbra, 3004-504 Coimbra, Portugal \\ ${ }^{2}$ IMAR, University of Coimbra, 3004-517 Coimbra, Portugal \\ ${ }^{3}$ Department of Biochemistry, University of Coimbra, Apartado 3126, 3001-401 Coimbra, Portugal
}

Correspondence

Paula V. Morais

pvmorais@ci.uc.pt
Strains TRF-1 ${ }^{\top}$ and TC-9 were isolated from transfer spikes of two separate bottles containing $0.9 \% \mathrm{NaCl}$ (physiological saline) solution used repeatedly to wash wounds in hospital wards, months apart. Phylogenetic analysis of $16 \mathrm{~S}$ rRNA gene sequences revealed that strains TRF-1 ${ }^{\top}$ and TC-9 formed a distinct branch within the family Bacillaceae most closely related to the members of the genus Jeotgalicoccus. The two strains, with identical 16S rRNA gene sequences, showed sequence similarities of 89.8-93.9\% with species of Jeotgalicoccus, $91.1-91.8 \%$ with species of Salinicoccus and 89.1-89.7\% with species of Staphylococcus. Strains TRF-1 ${ }^{\top}$ and TC-9 are Gram-positive, non-spore-forming and non-motile cocci, with an optimum growth temperature of about $37{ }^{\circ} \mathrm{C}$. Strain TRF-1 $1^{\top}$ grew optimally in medium containing $3 \%(\mathrm{w} / \mathrm{v}) \mathrm{NaCl}$ (maximum about $14 \% \mathrm{NaCl}$ ), while strain TC-9 grew optimally in medium with $1 \%(\mathrm{w} / \mathrm{v}) \mathrm{NaCl}$. Both strains produce a brown pigment when grown in the presence of $\mathrm{NaCl}$. The cell-wall peptidoglycan is of the $A 3 \alpha$ type with a cross-linkage containing the peptide L-Lys-Gly ${ }_{4}-L-S e r-$ Gly. The major respiratory quinones are menaquinone 7 (MK-7) and menaquinone 8 (MK-8), the major fatty acids are straight-chain $\mathrm{C}_{14: 0}$ and $\mathrm{C}_{16: 0}$ (more than $85 \%$ of the total) and the major polar lipid is an unknown aminophospholipid. The DNA G+C content is $33.5 \mathrm{~mol} \%$. On the basis of the phylogenetic analysis and physiological and biochemical characteristics, we are of the opinion that strains TRF-1 ${ }^{\top}$ and TC-9 represent a novel species of a new genus, for which we propose the name Nosocomiicoccus ampullae gen. nov., sp. nov. The type strain of

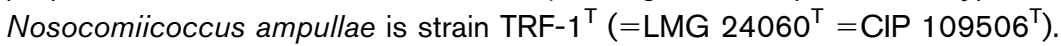

In some hospital wards, the same bottle of physiological saline is used repeatedly for topical washing of wounds and can become contaminated with micro-organisms. Microbial colonization of these bottles and the transfer spikes was examined in the course of a study to assess their colonization with bacteria after frequent usage. Two halotolerant and moderately halophilic cocci (strains TRF- $1^{\mathrm{T}}$ and TC-9) were recovered, among a large number of other isolates, that were most closely related phylogenetically to the species of the genus Jeotgalicoccus. The genus Jeotgalicoccus was proposed by Yoon et al. (2003) to accommodate strains of two species, Jeotgalicoccus psychrophilus and Jeotgalicoccus halotolerans, isolated from a

The GenBank/EMBL/DDBJ accession numbers for the 16S rRNA gene sequences of strains TRF- $1^{\top}$ and TC-9 are EU240886 and EU240887.

Maximum-likelihood and maximum-parsimony trees based on 16S rRNA gene sequences are available as supplementary material with the online version of this paper. fermented Korean food called jeotgal, which is prepared with seawater. A third species isolated from the mouth of an elephant seal was named Jeotgalicoccus pinnipedialis (Hoyles et al., 2004). The species of the genus Jeotgalicoccus are characterized by having menaquinone MK-7 as predominant isoprenoid quinone, a cell-wall peptidoglycan of the A3 $\alpha$ type based on L-Lys-L-Gly ${ }_{3-4}-\mathrm{L}-\mathrm{Ala}(\mathrm{Gly})$ and DNA G + C contents of 36-42 mol\% (Yoon et al., 2003). On the basis of the data presented here, we propose that strains TRF- $1^{\mathrm{T}}$ and TC-9 represent a species of a distinct, novel genus.

Strains TRF- $1^{\mathrm{T}}$ and TC-9 were isolated on two occasions from separate transfer spikes of plastic bottles of physiological saline manipulated by hospital personnel to wash wounds. The transfer spikes were sampled using sterile cotton swabs, which were applied directly on Columbia blood agar medium and incubated aerobically at $37^{\circ} \mathrm{C}$ for $72 \mathrm{~h}$. Isolates were purified by streaking on brain heart 
infusion agar (BHIA). All strains were preserved at $-80{ }^{\circ} \mathrm{C}$ in heart infusion broth (BD) containing $15 \%(\mathrm{v} / \mathrm{v})$ glycerol. J. pinnipedialis CCUG $42722^{\mathrm{T}}$ was obtained from the Culture Collection, University of Gothenburg, Sweden, and J. halotolerans CIP $107958^{\mathrm{T}}$ and J. psychrophilus CIP $107952^{\mathrm{T}}$ were obtained from the Institut Pasteur, France.

Several media were assessed for growth of strains TRF- $1^{\mathrm{T}}$ and TC-9, namely BHIA (Cultimed), heart infusion agar (BD), Luria-Bertani agar (LBA; Difco), tryptic soy agar (Sigma), marine agar (Difco), Columbia agar base (bioMérieux) with $5 \%(\mathrm{v} / \mathrm{v})$ sheep blood, Chapman agar (Difco) and MacConkey agar (bioMérieux). The organisms were grown under an aerobic, $5 \% \mathrm{CO}_{2}$ atmosphere and under anaerobic conditions (Genebox) on BHIA at 30 and $37{ }^{\circ} \mathrm{C}$ for 7 days. The temperature range and optimum for growth were tested on BHIA incubated at 4, 22, 30, 37, 40, 45 and $50{ }^{\circ} \mathrm{C}$ and growth was examined after 10 days. The ability to grow in the presence of $\mathrm{NaCl}$ was examined at $37^{\circ} \mathrm{C}$ on BHIA supplemented with $\mathrm{NaCl}$ at final concentrations of $2,5,10,14,15,16,20$ and $21 \%(\mathrm{w} / \mathrm{v})$ and on LBA supplemented with 1, 3, 5 and $10 \% \mathrm{NaCl}$ (w/ v). Cell morphology and motility were examined by phasecontrast microscopy after growth on BHIA at $37^{\circ} \mathrm{C}$ for $24 \mathrm{~h}$. The Gram reaction and the presence of cytochrome oxidase and catalase were determined after $24 \mathrm{~h}$ of incubation as described by Smibert \& Krieg (1981). Enzyme profiles were determined using the API ZYM, API STAPH, API NE and API CORYNE test strips (bioMérieux) according to the manufacturer's instructions. Single-carbon-source assimilation was determined using API $50 \mathrm{CH}$ test strips (bioMérieux) with Degryse medium containing $0.05 \%(\mathrm{w} / \mathrm{v})$ yeast extract (Degryse et al., 1978). The $\mathrm{pH}$ range for growth was examined at $30{ }^{\circ} \mathrm{C}$ in BHIA medium with the $\mathrm{pH}$ adjusted by the addition of $50 \mathrm{mM}$ MES ( $\mathrm{pH} \mathrm{5,6}$ and 7), TAPS ( $\mathrm{pH} 8$ and 9) or CAPSO (pH 10) (Branco et al., 2004).

Cultures used for polar lipid analysis were grown on BHIA with $1 \% \mathrm{NaCl}$ at $37{ }^{\circ} \mathrm{C}$ for $48 \mathrm{~h}$ (except for J. psychrophilus CIP $107952^{\mathrm{T}}$, which was grown at $25^{\circ} \mathrm{C}$ ). Cultures were harvested and lyophilized, lipids were extracted and onedimensional TLC was performed as described previously (Collins et al., 1980). Lipoquinones were extracted from freeze-dried cells, purified by TLC and identified by HPLC (Tindall, 1989). Cultures for fatty acid analysis were grown on BHIA with $1 \% \mathrm{NaCl}$ and strains TRF- $1^{\mathrm{T}}$ and TC-9 were also grown on LBA plates, in sealed plastic plates, for $48 \mathrm{~h}$ (Morais et al., 2004); fatty acids were identified using the standard MIS Library Generation software (Microbial ID). Purification of cell wall and the acquisition of amino acids and peptides in cell-wall hydrolysates were performed by the method of Schleifer \& Kandler (1972). The terminal amino acid of the interpeptide bridge was determined by dinitrophenylation as described by Schleifer (1985).

The $\mathrm{G}+\mathrm{C}$ content of the genome was determined by HPLC as described by Mesbah et al. (1989). The 16S rRNA gene was sequenced as described by Morais et al. (2004).
Phylogenetic analysis was performed using the ARB software package (Ludwig et al., 2004). Phylogenetic trees were constructed using maximum-parsimony, maximum-likelihood (Felsenstein, 1981) and neighbour-joining (Saitou \& Nei, 1987) algorithms. The tree topologies were evaluated by performing bootstrap analysis (Felsenstein, 1985) of 1000 datasets.

Strains TRF- $1^{\mathrm{T}}$ and TC-9 were Gram-positive, non-sporeforming and non-motile cocci. After 2 days incubation on BHIA, colonies were small and light yellow in colour. The new isolates produced very large cell aggregates in medium without additional $\mathrm{NaCl}$. Both strains produced a brown pigment in older cultures in the presence of $\mathrm{NaCl}$. Both organisms grew on all media examined at $37{ }^{\circ} \mathrm{C}$, with the exception of Chapman agar. Growth was best on BHIA and LBA. Strains TRF- $1^{\mathrm{T}}$ and TC-9 had a very narrow growth temperature range $\left(30-45{ }^{\circ} \mathrm{C}\right)$ with an optimum at about $37{ }^{\circ} \mathrm{C}$ (Table 1). Strains TRF- $1^{\mathrm{T}}$ and TC-9 grew aerobically and under microaerophilic conditions but did not grow anaerobically. In this study, we found that $J$. halotolerans CIP $107958^{\mathrm{T}}$ and J. psychrophilus CIP $107952^{\mathrm{T}}$ did not grow anaerobically, despite the previous report that they did (Yoon et al., 2003). The organisms grew in media without additional salt, but growth was better in the presence of $\mathrm{NaCl}$; strain TRF-1 ${ }^{\mathrm{T}}$ grew better in LBA containing $3 \%(\mathrm{w} / \mathrm{v}) \mathrm{NaCl}$, but strain TC-9 grew better in the same medium containing $1 \%(\mathrm{w} / \mathrm{v}) \mathrm{NaCl}$. Both organisms also grew in LBA containing $14 \%(w / v) ~ \mathrm{NaCl}$ but, in BHIA, strain TRF- $1^{\mathrm{T}}$ grew with a maximum of $10 \%$ $\mathrm{NaCl}$.

Assimilation of single carbon sources using API $50 \mathrm{CH}$ was not observed, and only L-arabinose gave a weak positive fermentation reaction using API NE (Table 1). Unlike the species of the genus Jeotgalicoccus, which possess very high levels of iso- and anteiso-branched fatty acids, we found only straight-chain fatty acids in the two new isolates; this unusual composition was not dependent on the growth medium or the concentration of salt in the medium (Table 2 ). The polar lipid pattern of strain TRF- $1^{\mathrm{T}}$ revealed the presence of an unidentified major aminophospholipid, not present in the species of the genus Jeotgalicoccus, and several unidentified minor phospholipids and aminolipids (Fig. 1). All species of the genus Jeotgalicoccus examined possessed diphosphatidylglycerol and phosphatidylglycerol along with several aminolipids. MK-7 and MK-8 were found in equimolar proportions in both strains.

The almost-complete 16S rRNA gene sequence was determined for strains TRF- ${ }^{\mathrm{T}}$ and TC-9 (1502 and $1490 \mathrm{bp}$, respectively). 16S rRNA gene sequences were aligned with representative members of the phylum Firmicutes, showing these organisms to be most closely related to the cluster comprising species of the genus Jeotgalicoccus, but the two strains formed a distinct line supported by bootstrap analysis at a confidence level of $71 \%$ (Fig. 2). Furthermore, this tree topology was also found using the maximum-likelihood and maximum- 
Table 1. Phenotypic characteristics that differentiate strain TRF-1 ${ }^{\top}$ (Nosocomiicoccus ampullae gen. nov., sp. nov.) from the type strains of described species of Jeotgalicoccus

Data for strain TRF-1 $1^{\mathrm{T}}$ and J. pinnipedialis CCUG $42722^{\mathrm{T}}$ were obtained in this study. Fatty acid compositions of all strains were determined in this study (see Table 2); other data for J. halotolerans YKJ-101 ${ }^{\mathrm{T}}$ and J. psychrophilus YKJ-115 ${ }^{\mathrm{T}}$ were taken from Yoon et al. (2003). +, Positive; -, negative; w, weak.

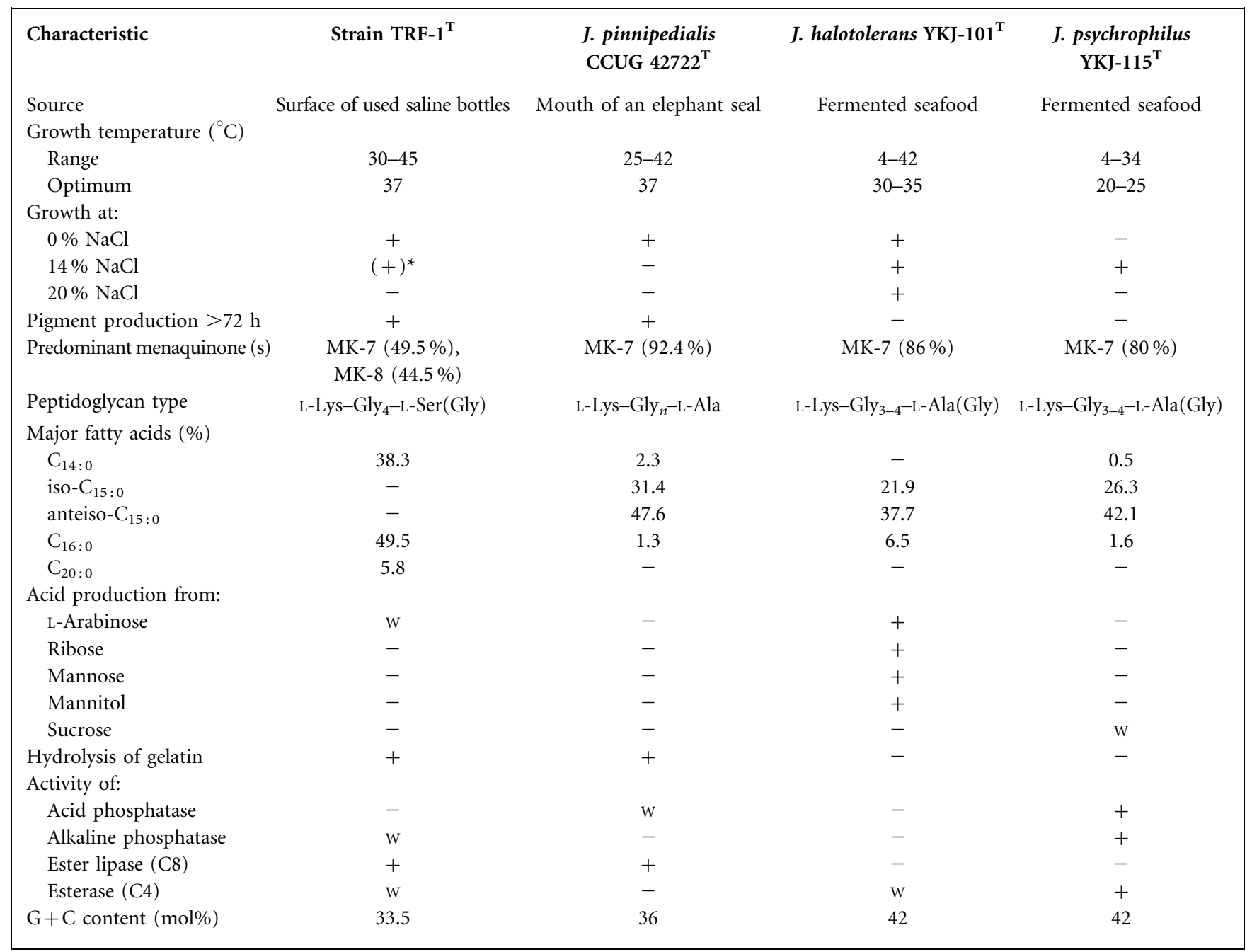

${ }^{*}$ Growth was positive on LBA but not on BHIA.

parsimony algorithms (Supplementary Figs S1 and S2, available in IJSEM Online). The novel strains clustered with the type strains of J. psychrophilus, J. halotolerans and $J$. pinnipedialis at $16 \mathrm{~S}$ rRNA gene sequence similarities of $89.8,90.9$ and $93.9 \%$, respectively.

Nucleotide signatures were found in the 16S rRNA gene sequences of strains TRF- $1^{\mathrm{T}}$ and TC-9 that distinguished the sequences from those of species of the genera Jeotgalicoccus and Salinicoccus (Table 3). Moreover, the type strain of $J$. pinnipedialis has specific nucleotide signatures within its $16 \mathrm{~S}$ rRNA gene that distinguish this organism from the other species of Jeotgalicoccus, indicating that the classification of J. pinnipedialis should be reassessed.
The new taxon represented by strains TRF-1 ${ }^{\mathrm{T}}$ and TC-9 can be distinguished from species of the genus Jeotgalicoccus primarily by the fatty acid composition. The type strains of J. psychrophilus, J. halotolerans and J. pinnipedialis possess large amounts of iso- and anteisobranched fatty acids, while strains TRF- $1^{\mathrm{T}}$ and TC-9 do not. Moreover, the peptidoglycan of the species of the genus Jeotgalicoccus possesses an interpeptide bridge containing L-Lys-Gly ${ }_{n}-\mathrm{L}-\mathrm{Ala}(\mathrm{Gly})$, while the two novel strains possess an interpeptide bridge composed of L-Lys$\mathrm{Gly}_{4}$-L-Ser(Gly). The absence of diphosphatidylglycerol and phosphatidylglycerol in strain TRF- $1^{\mathrm{T}}$ differentiate this organism from the species of the genus Jeotgalicoccus and from the species of the genus Salinicoccus for which the polar lipids have been examined. The observation that 
Table 2. Fatty acid compositions of strains $T R F-1^{\top}$ and $T C-9$ and type strains of the genus Jeotgalicoccus

Reference strains: 1 , J. pinnipedialis CCUG $42722^{\mathrm{T}}$; 2, J. halotolerans CIP $107958^{\mathrm{T}}$; 3, J. psychrophilus CIP $107952^{\mathrm{T}}$. Fatty acid profiles of reference type strains were determined after growth on BHIA with $1 \% \mathrm{NaCl}$. All data were obtained in this study. - , Not detected or present at less than $0.5 \%$.

\begin{tabular}{|c|c|c|c|c|c|c|c|}
\hline \multirow[t]{2}{*}{ Fatty acid } & \multicolumn{2}{|c|}{ Strain TRF-1 ${ }^{\mathrm{T}}$} & \multicolumn{2}{|c|}{ Strain TC-9 } & \multirow[t]{2}{*}{1} & \multirow[t]{2}{*}{2} & \multirow[t]{2}{*}{3} \\
\hline & $\mathrm{BHIA}+1 \% \mathrm{NaCl}$ & $\mathrm{LBA}+3 \% \mathrm{NaCl}$ & BHIA + $1 \% \mathrm{NaCl}$ & $\mathrm{LBA}+3 \% \mathrm{NaCl}$ & & & \\
\hline iso- $\mathrm{C}_{13: 0}$ & - & - & - & - & 1.0 & - & - \\
\hline anteiso- $\mathrm{C}_{13: 0}$ & - & - & - & - & 0.5 & - & - \\
\hline iso- $\mathrm{C}_{14: 0}$ & - & - & - & - & 1.1 & 1.5 & 2.3 \\
\hline $\mathrm{C}_{14: 0}$ & 35.0 & 38.3 & 43.8 & 32.3 & 2.3 & 0.8 & 0.5 \\
\hline iso- $\mathrm{C}_{15: 0}$ & 1.4 & - & - & - & 31.4 & 21.9 & 26.3 \\
\hline anteiso- $\mathrm{C}_{15: 0}$ & - & - & - & - & 47.6 & 37.7 & 42.1 \\
\hline $\mathrm{C}_{16: 1} \omega 7 c$ alcohol & 3.0 & 1.1 & 0.5 & 2.6 & - & 0.8 & 4.2 \\
\hline iso- $\mathrm{C}_{16: 0}$ & - & - & - & - & 1.3 & 6.5 & 1.6 \\
\hline $\mathrm{C}_{16: 1} \omega 11 c$ & - & - & - & - & - & - & 2.2 \\
\hline $\mathrm{C}_{16: 0}$ & 50.2 & 49.5 & 47.9 & 52.8 & 2.3 & 3.5 & 0.6 \\
\hline iso- $\mathrm{C}_{17: 1} \omega 10 c$ & - & - & - & - & 2.5 & 7.1 & 6.5 \\
\hline Summed feature $4^{*}$ & - & 0.7 & - & - & - & - & 1.8 \\
\hline iso- $\mathrm{C}_{17: 0}$ & - & - & - & - & 3.0 & 5.8 & 3.3 \\
\hline anteiso- $\mathrm{C}_{17: 0}$ & - & - & - & - & 4.7 & 9.2 & 5.5 \\
\hline $\mathrm{C}_{18: 1} \omega 9 c$ & 0.8 & 0.7 & - & 1.0 & - & - & - \\
\hline $\mathrm{C}_{18: 0}$ & 2.5 & 3.0 & 2.6 & 3.1 & - & - & - \\
\hline iso- $\mathrm{C}_{19: 0}$ & - & - & - & - & 0.5 & 1.3 & 1.0 \\
\hline $\mathrm{C}_{20: 0}$ & 4.1 & 5.8 & 2.6 & 6.7 & - & - & - \\
\hline
\end{tabular}

${ }^{*}$ Summed feature 4 contained iso- $\mathrm{C}_{17: 1} \mathrm{I}$ and/or anteiso- $\mathrm{C}_{17: 1} \mathrm{~B}$, which could not be separated by GLC with the MIDI system.

strains TRF- $1^{\mathrm{T}}$ and TC-9 have MK-7 and MK-8 in similar molar ratios $(49.5: 44.5)$, unlike the species of Jeotgalicoccus, where $\mathrm{MK}-7$ is the major respiratory quinone, may also indicate that the novel organisms belong to a new genus. Phylogenetic analyses of the $16 \mathrm{~S}$ rRNA gene indicated that the strains formed a branch that

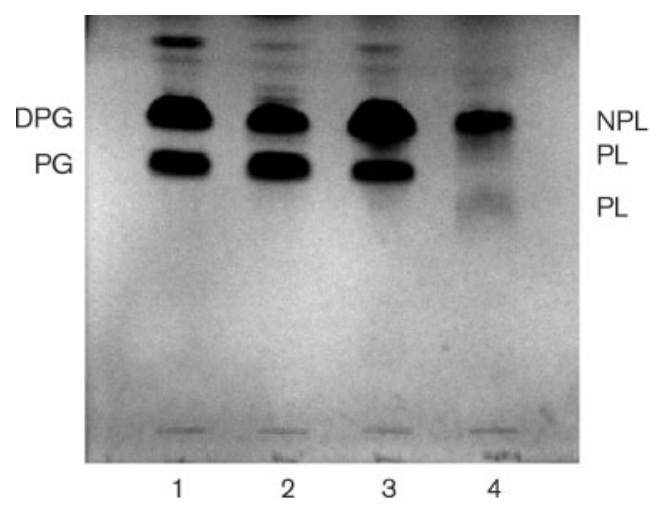

Fig. 1. One-dimensional TLC of polar lipids of $J$. halotolerans CIP $107958^{\top}$ (lane 1), J. psychrophilus CIP $107952^{\top}$ (2), J. pinnipedialis CCUG $42722^{\top}$ (3) and strain TRF-1 ${ }^{\top}$ (4). DPG, Diphosphatidylglycerol; NPL, unidentified aminophospholipid; PG, phosphatidylglycerol; PL, unidentified phospholipid. was almost equidistant from the type strains of the genus Salinicoccus (91.1-91.8\%), J. halotolerans (89.8\%) and J. psychrophilus (90.9\%), but slightly more closely related to the type strain of J. pinnipedialis (93.9\%). Since phenotypic characterization did not allow us to make a decision on the classification of $J$. pinnipedialis, it is our opinion that the organism should be retained as a member of the genus Jeotgalicoccus, while the novel strains should be assigned to a new genus, based on the phenotypic and phylogenetic evidence gathered here. We therefore propose that strains TRF- $1^{\mathrm{T}}$ and TC-9 represent a novel species of a new genus, for which we offer the name Nosocomiicoccus ampullae gen. nov., sp. nov.

\section{Description of Nosocomiicoccus gen. nov. Morais, Chung and da Costa}

Nosocomiicoccus ( $\mathrm{No}^{\prime}$ so.co'mi.i.coc'cus. L. n. nosocomium hospital; N.L. masc. n. coccus a coccus from Gr. n. kokkos a grain, berry; N.L. masc. n. Nosocomiicoccus a coccus isolated in a hospital).

Gram-positive, non-motile, non-spore-forming, coccusshaped cells. Chemo-organotrophic, mesophilic, slightly halophilic and aerobic. Optimum $\mathrm{pH}$ for growth is around neutral. Catalase- and oxidase-positive. Cell-wall peptidoglycan contains L-lysine at position 3 and A $3 \alpha$-type crosslinkage peptide. Predominant menaquinones are MK-7 


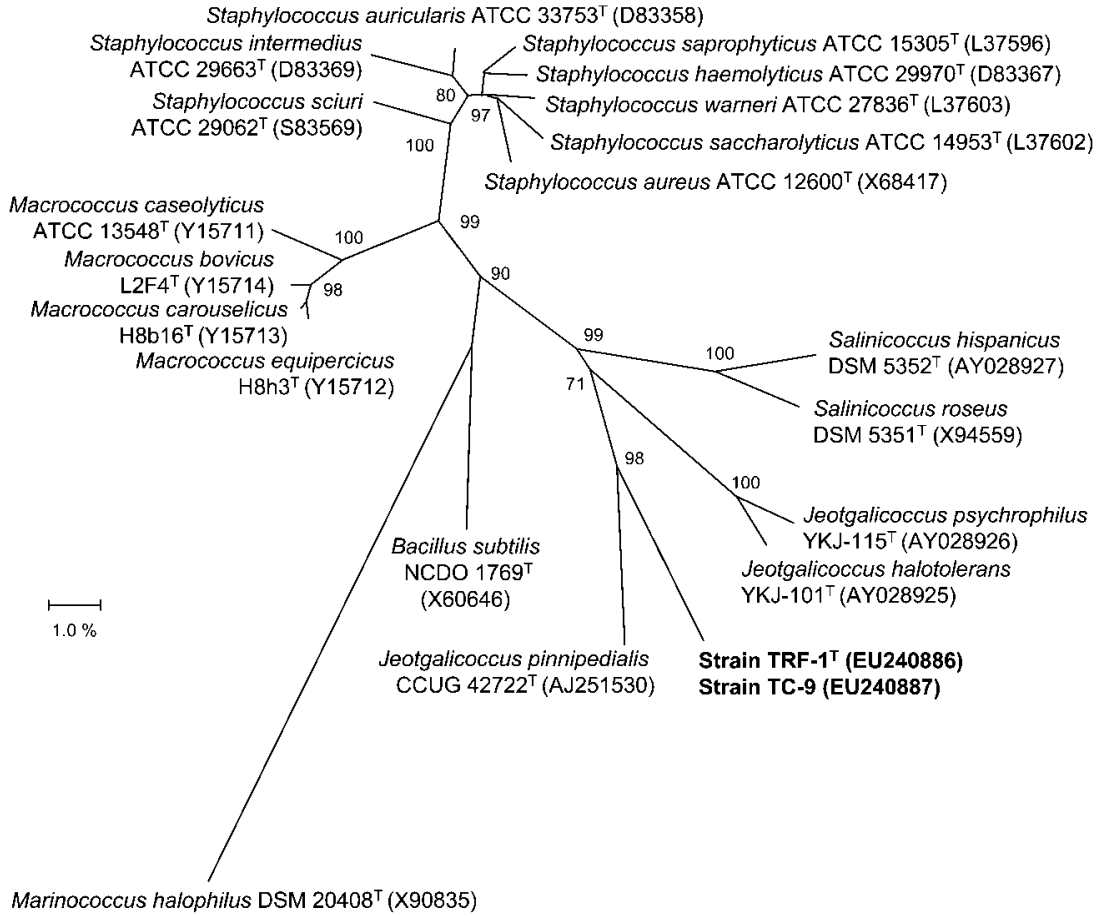

Fig. 2. $16 \mathrm{~S}$ rRNA gene sequence-based phylogeny showing the relationships of strains TRF- ${ }^{\mathrm{T}}$ and TC-9 and closely related taxa. The phylogenetic dendrogram was constructed from the distance matrix using the neighbourjoining method. Numbers at branching points represent bootstrap percentages from 1000 data samplings. Bar, 1 inferred substitution per 100 nucleotide positions. and MK-8. The major polar lipid is an unknown aminophospholipid. Fatty acids are predominantly straight-chain saturated and unsaturated. The genus belongs to the phylum Firmicutes. The type species is Nosocomiicoccus ampullae.

\section{Description of Nosocomiicoccus ampullae sp. nov. Morais, Chung and da Costa}

Nosocomiicoccus ampullae (am.pul'lae. L. gen. n. ampullae of a bottle, of a flask, referring to the isolation of the first strains from bottles containing physiological saline).

Colonies are small, smooth, glistening, convex, circular and light yellow in colour after 2 days incubation on BHIA and produce a diffusible pigment in cultures older than $72 \mathrm{~h}$ in the presence of $\mathrm{NaCl}$. Growth occurs in media without added $\mathrm{NaCl}$ and with $\mathrm{NaCl}$ up to $10 \%(w / v)$. Cell aggregates are formed in liquid medium during growth without $\mathrm{NaCl}$. Optimal growth temperature is $30-37{ }^{\circ} \mathrm{C}$. Optimal $\mathrm{pH}$ for growth is 7.5-8.0. Does not grow anaerobically. Ureasenegative. Gelatin is hydrolysed. Weak acid production is obtained from L-arabinose using the API NE test strip, but no other substrates are fermented or assimilated using API $50 \mathrm{CH}$. Nitrate is not reduced to nitrite. Major fatty acids are $\mathrm{C}_{16: 0}$ and $\mathrm{C}_{14: 0}$. The DNA $\mathrm{G}+\mathrm{C}$ content of the type strain is $33.5 \mathrm{~mol} \%$ (determined by HPLC).

The type strain, TRF- ${ }^{\mathrm{T}}\left(=\mathrm{LMG} 24060^{\mathrm{T}}=\mathrm{CIP} 109506^{\mathrm{T}}\right)$, was isolated from the transfer spike of a bottle containing physiological saline. Strain TC-9, isolated from a similar source, is another strain of the species.

Table 3. $16 \mathrm{~S}$ rRNA gene sequence signatures of strains $\mathrm{TRF}-1^{\top}$ and $\mathrm{TC}-9$ and phylogenetically related species of the genera Jeotgalicoccus and Salinicoccus

Positions are given relative to the sequence of Escherichia coli. Signatures for Jeotgalicoccus relate to the sequences of J. halotolerans YKJ-101 ${ }^{\mathrm{T}}$ and $J$. psychrophilus YKJ-115 ${ }^{\mathrm{T}}$, whereas those for Salinicoccus relate to all type strains of the genus.

\begin{tabular}{|c|c|c|c|c|}
\hline Positions & TRF- ${ }^{\mathrm{T}}$ and TC-9 & J. pinnipedialis A/G14/99/10 & Jeotgalicoccus & Salinicoccus \\
\hline $193-194$ & $\mathrm{AU}$ & GG & GG & $(\mathrm{G} / \mathrm{C})^{b} \mathrm{G}$ \\
\hline $1270-1273$ & $\mathrm{AGU}$ & GGC & GGC & $\mathrm{GG}(\mathrm{C} / \mathrm{U})^{c}$ \\
\hline
\end{tabular}

${ }^{*}$ Nucleotide substitutions detected in some strains as follows: $a$, U in S. jeotgali S2R53-5 ${ }^{\mathrm{T}}$ and S. siamensis PN1-2 ${ }^{\mathrm{T}}$; $b, \mathrm{C}$ in $S$. kunmingensis YIM $\mathrm{Y} 15^{\mathrm{T}} ; c, \mathrm{U}$ in S. siamensis $\mathrm{PN} 1-2^{\mathrm{T}}$. 


\section{Acknowledgements}

This research was funded by the Fundação para a Ciência e Tecnologia (FCT), Portugal, under the POCTI and FEDER programs, contract POCTI/BSE/42414/2001. A. P. C. was supported by a grant from the FCT. We thank Dr Peter Schumann (DSMZ, Germany) for the peptidoglycan analysis and Dr Jean Euzéby (Toulouse, France) for assistance with the etymology of the new name.

\section{References}

Branco, R., Alpoim, M. C. \& Morais, P. V. (2004). Ochrobactrum tritici strain 5 bvl1 - characterization of a $\mathrm{Cr}(\mathrm{VI})$-resistant and $\mathrm{Cr}(\mathrm{VI})$ reducing strain. Can J Microbiol 50, 697-703.

Collins, M. D., Goodfellow, M. \& Minnikin, D. F. (1980). Fatty acid, isoprenoid quinone and polar lipid composition in the classification of Curtobacterium and related taxa. J Gen Microbiol 118, 29-37.

Degryse, E., Glansdorff, N. \& Pierard, A. (1978). A comparative analysis of extreme thermophilic bacteria belonging to the genus Thermus. Arch Microbiol 117, 189-196.

Felsenstein, J. (1981). Evolutionary trees from DNA sequences: a maximum likelihood approach. J Mol Evol 17, 368-376.

Felsenstein, J. (1985). Confidence limits on phylogenies: an approach using the bootstrap. Evolution 39, 783-791.

Hoyles, L., Collins, M. D., Foster, G., Falsen, E. \& Schumann, P. (2004). Jeotgalicoccus pinnipedialis sp. nov., from a southern elephant seal (Mirounga leonina). Int J Syst Evol Microbiol 54, 745-748.

Ludwig, W., Strunk, O., Westram, R., Richter, L., Meier, H., Yadhukumar, Buchner, A., Lai, T., Steppi, S. \& other authors
(2004). ARB: a software environment for sequence data. Nucleic Acids Res 32, 1363-1371.

Mesbah, M., Premachandran, U. \& Whitman, W. B. (1989). Precise measurement of the $\mathrm{G}+\mathrm{C}$ content of deoxyribonucleic acid by high-performance liquid chromatography. Int J Syst Bacteriol 39, 159167.

Morais, P. V., Francisco, R., Branco, R., Chung, A. P. \& da Costa, M. S. (2004). Leucobacter chromiireducens sp. nov., and Leucobacter aridicollis sp. nov., two new species isolated from a chromium contaminated environment. Syst Appl Microbiol 27, 646-652.

Saitou, N. \& Nei, M. (1987). The neighbor-joining method: a new method for reconstructing phylogenetic trees. Mol Biol Evol 4, 406425.

Schleifer, K. H. (1985). Analysis of the chemical composition and primary structure of murein. Methods Microbiol 18, 123-156.

Schleifer, K. H. \& Kandler, O. (1972). Peptidoglycan types of bacterial cell walls and their taxonomic implications. Bacteriol Rev 36, 407-477.

Smibert, R. M. \& Krieg, N. R. (1981). General characterization. In Manual of Methods for General Bacteriology, pp. 411-442. Edited by P. Gerhardt, R. G. E. Murray, R. N. Costilow, E. W. Nester, W. A. Wood, N. R. Krieg \& G. B. Phillips. Washington, DC: American Society for Microbiology.

Tindall, B. J. (1989). Fully saturated menaquinones in the archaebacterium Pyrobaculum islandicum. FEMS Microbiol Lett 60, 251254.

Yoon, J.-H., Lee, K.-C., Weiss, N., Kang, K. H. \& Park, Y.-H. (2003). Jeotgalicoccus halotolerans gen. nov., sp. nov. and Jeotgalicoccus psychrophilus sp. nov., isolated from the traditional Korean fermented seafood jeotgal. Int J Syst Evol Microbiol 53, 595-602. 